use of the new metric charts as and when these become available. Along with these changes to books and publications we can expect the introduction of metric tide gauges, and of echo sounders calibrated not in feet or fathoms but in metres. In a few years time even those yachtsmen who normally never correct their charts, or who do not think about renewing them until they are covered with cocoa stains, will be forced to work in metres.

No doubt we shall get accustomed to the change, but there is one small item of equipment which apparently has not been metricated-the humble lead line. Admittedly its use is now greatly restricted, but any sea-going vessel should surely carry one, as a stand-by in the event of failure of the echo sounder and for periodical checks on its accuracy. It will obviously be inconvenient to perpetuate the traditional markings when fathoms are forgotten.

The Hydrographer of the Navy has introduced the following markings for survey work, where lead lines are still used-mainly to calibrate echo sounders for variations of the speed of sound in water.

I, I I and 2 I metres-one strip of leather

2, 12 and 22 metres-two strips of leather

3,13 and 23 metres-blue bunting

4,14 and 24 metres-green and white bunting

5,15 and 25 metres-white bunting

6,16 and 26 metres-green bunting

7,17 and 27 metres-red bunting

8 , 18 and 28 metres-blue and white bunting

9 , 19 and 29 metres-red and white bunting

Io metres

-leather with a hole in it

20 metres

-leather with a hole in it and 2 strips of leather

30 metres

-leather with a hole in it and 3 strips of leather

40 metres

-leather with a hole in it and 4 strips of leather

50 metres

-leather with a hole in it and 5 strips of leather

All 0.2 metre

markings -a piece of mackerel line

One advantage of this system is that the metre markings almost correspond to the fathom 'marks' of the conventional lead line. A 20 metre (or 10 fathom) line is adequate for most yachting purposes.

While it is not suggested that European standardization is necessary, it does seem desirable that all British seamen should use common markings, and that the working system already used by the Hydrographer would be suitable for this purpose.

\title{
The Treble Bearing Problem
}

\section{Charles H. Cotter}

IT may come as a surprise to many navigators that the interesting and valuable, although seemingly little-used, method in which three successive bearings of a single fixed mark are used to find course made good, has a history of not more than about half a century. 
When two or more suitably placed marks are in sight the course made good may readily be found from a series of fixes by cross bearings, and this technique is commonly used by coastal navigators. When, however, a single mark alone is available the reliability of running fixes depends upon the accuracy of estimations of courses and distances made good in the intervals between successive bearings. A table for finding the distance of a mark from two bearings and the distance run in the interval between observations was inserted in the first edition of Raper's Practice of Navigation ${ }^{1}$ in which the author informs his readers that the table was constructed at the suggestion of Sir Francis Beaufort and that it first appeared in the Nautical Magazine. ${ }^{2}$

The treble bearing problem appears to have been introduced by Captain H. H. Edmonds in a small work ${ }^{3}$ published in Sydney in 1919. Edmonds' method provides a tabular solution to the problem of finding course made good from three successive observations of a fixed landmark or light. The author explained that the problem includes three cases: first, when the bearings are observed at equal angular intervals; second, when the bearings are observed at equal time intervals; and third, when both angular and time intervals are unequal. He chose the first case and published a suitable double-entry table with arguments Common Angular Interval and Quotient $I_{1} / I_{2}, I_{1}$ and $I_{2}$ being the respective time intervals between the first and second, and second and third, observations. Entering the table with the appropriate arguments the angle which the courseline over the ground makes with the first line of bearing is lifted as respondent.

H. B. Goodwin described Edmonds' table in 19204.5 and suggested that a similar table based on equal time intervals has a distinct advantage over the former if only to avoid the necessity of working out a quotient. Moreover, it is simpler to measure time intervals by bridge clock than it is to dodge around the compass waiting for the mark to come on to the required bearings. In his second paper ${ }^{5}$ Goodwin analysed the general problem (case three above) before describing his suggested table based on equal time intervals.

The arguments in Goodwin's table are $d_{1}$ and $d_{2}$, the differences respectively between the first and second, and the second and third, bearings; against the respondents Angle of Inclination of Course to First Line of Bearing and a factor $F$. By taking the product of $F$ and the distance of the mark at the time of the first bearing (if known), the distance-off at the time of the third bearing is determined. Goodwin's table was included in the Norie's Collection, making its first appearance in the 1924 edition 6 in which it was remarked that the table '... should be a boon to navigators'. It was discontinued in the 1956 edition, 7 the editor stating in his Preface that the table was '... little used, so (its) disappearance should not be seriously regretted'.

Edmonds in introducing his table expressed the opinion that the treble bearing methods might prove of service to air navigators. And, indeed, the method of equal time intervals was described in an early work on air navigation 8 whose author apparently was unacquainted with Edmonds' work.

Goodwin in his second paper mentioned that the general case of the treble bearing problem appeared in Board of Trade examinations for mates and masters at least as early as I 14 , and he assigned full credit to the 'very able examiners' for drawing attention to 'this important problem'. The solution required by the Board of Trade examiners was, undoubtedly, a graphical one to be performed in a chartwork examination. It is evident that navigators who use the method in 
practice (and these seem to be few in number) prefer the geometrical solution to that obtained from tables and it is not surprising that the tables are now obsolete. A complete description of the three-bearing problem with anlayses similar to those made by Goodwin is to be found in the first edition of the useful book ${ }^{9}$ on chartwork by Stewart and Stephen published a half century ago. It also appeared in the second edition of Nicholls's Concise Guide, 10 volume 2.

The geometrical construction given by Goodwin and suggested by Stewart and Stephen is relatively clumsy; requiring as it does a 'ratio line' to be drawn through the charted position of the observed mark at right angles to the middle bearing. That it should be drawn at right angles is of no significance: in fact any angle will do. The neatest method is to use the first (or last) position line and its extension through the charted position of the mark as the 'ratio line'. This provides for a speedier solution with fewer lines on the chart than the generally recommended method.

As a footnote it is of interest that William Wales, in his revised edition of Robertson's textbook on navigation designed for the pupils of the Royal Mathematical School, Christ's Hospital, 11 described a method for finding 'the course steered by a ship seen at a distance'. The method required the observer to be stationary (in a ship lying to). By taking three bearings at two known intervals of time, and using a geometrical construction identical to that given by Goodwin, the apparent course of the ship 'seen at a distance' may be found. This interesting problem was given at least as early as $\mathrm{I} 786$.

\section{REFEREN CES}

1 Raper, H. (1940). The Practice of Navigation. London.

2 Anon. (1832). The Naut. Mag. I London.

3 Edmonds, H. H. (1 9 I 9). Course Angle Tables for Finding Course Made Good. Sydney.

4 Goodwin, H. B. (1920). An Important Development in Coastal Navigation. The Naut. Mag., 103.

5 Goodwin, H. B. (1920). A Course Angle Table based on Equal Intervals of Time. The Naut. Mag., 104.

6 Norie, J. W. (1924). A Complete Set of Nautical Tables. London.

7 Norie, J. W. (1956). Norie's Nautical Tables. New Edn. by F. N. Hopkins. London.

8 Dumbleton, J. E. (1920). Principles and Practice of Aerial Navigation. London.

9 Stewart, W. K. and Stephen, J. W. (1923). Modern Chartwork. Glasgow.

10 Maxwell, F. W. (1925). Nicholls's Concise Guide. Vol. 2. Glasgow.

11 Robertson, J. (1786). The Elements of Navigation. $5^{\text {th }} \mathrm{Edn}$. by W. Wales. London.

\section{'A Prospect of Navigation'}

\section{Mr. Shigeaki Mabuchi writes :}

It is interesting to consider navigation and the problem of traffic control with the common underlying concept of randomness, though Anderson's presentation seems more oriented to thermodynamics than to information theory. 1 But the underlying philosophy is the same : entropy never increases.

In order to decrease entropy without the help of Maxwell's demon we have to introduce work or energy, that is we measure the state of a specific object and control that state with the aid of the information gained. The trouble is 